\title{
Benchmarking Complications Associated With Esophagectomy
}

\author{
Donald E. Low ${ }^{1}$, MadhanKumar Kuppusamy ${ }^{1}$, Derek Alderson ${ }^{2}$, \\ Ivan Cecconello ${ }^{3}$, Andrew C. Chang ${ }^{4}$, Gail Darling ${ }^{5}$, Andrew Davies ${ }^{6}$, Xavier Benoit D'Journo ${ }^{7}$, \\ Suzanne S Gisbertz ${ }^{8}$, Michael Griffin ${ }^{9}$, Richard Hardwick ${ }^{10}$, Arnulf Hoelscher ${ }^{11}$, Wayne Hofstetter ${ }^{12}$, \\ Blair Jobe ${ }^{13}$, Yuko Kitagawa ${ }^{14}$, Simon Ying Kit Law ${ }^{15}$, Christophe Mariette ${ }^{16}$, Nick Maynard ${ }^{17}$, \\ Christopher Morse ${ }^{18}$, Philippe Nafteux ${ }^{19}$, Manuel Pera ${ }^{20}$, C S. Pramesh ${ }^{21}$, Sonia Puig ${ }^{22}$, \\ John V. Reynolds ${ }^{23}$, Wolfgang Schroeder ${ }^{24}$, Mark Smithers ${ }^{25}$, Bas Wijnhoven ${ }^{26}$ \\ 1 Virginia Mason Medical Center, Seattle, Washington USA; 2 The Royal College of Surgeons of England, London, UK; \\ 3 University of São Paulo, São Paulo, Brazil; 4 University of Michigan Health System, Ann Arbor, Michigan USA; \\ 5 Toronto General Hospital, Toronto, Canada; 6 St. Thomas' Hospital, London, UK; \\ 7 North Hospital - Aix Marseille University, Marseille, France; 8 Academic Medical Center, Amsterdam, The Netherlands; \\ 9 University of Newcastle upon Tyne, Newcastle, UK; 10 Cambridge OesophagoGastric Centre, Cambridge, UK; \\ 11 Agaplesion Markus Krankenhaus, Frankfurt, Germany; 12 MD Anderson Cancer Center, Houston, Texas USA; \\ 13 Allegheny Health System, Pittsburg, Pennsylvania USA; 14 Keio University, Tokyo, Japan; \\ 15 Queen Mary Hospital, Hong Kong, China; 16 University Hospital of Lille, Lille, France; \\ 17Oxford OesophagoGastric Centre, Oxford, UK; 18 Massachusetts General Hospital, Boston, Massachusetts USA; \\ 19 Katholieke Universiteit Leuven, Leuven, Belgium; 20 Hospital Universitario del Mar, Barcelona, Spain; \\ 21 Tata Memorial Hospital, Mumbai, India; 22 Queen Elizabeth Hospital, Birmingham, UK; \\ 23 Trinity College Dublin, Dublin, Ireland; 24 University of Cologne, Cologne, Germany; \\ 25 The University of Queensland, Brisbane, Australia; 26 Erasmus Medical Center, Rotterdam, The Netherlands;
}

\section{Corresponding author:}

\section{Donald E. Low, MD, FACS, FRCSC}

Head of Thoracic Surgery \& Thoracic Oncology

C6-GS, Virginia Mason Medical Center

1100 Ninth Ave, Seattle WA 98101

Email: donald.low @vmmc.org

Phone: (206) 223-6164

Fax: (206) 625-7245 


\section{ABSTRACT}

OBJECTIVE: Utilizing a standardized dataset with specific definitions to prospectively collect international data to provide a benchmark for complications and outcomes associated with esophagectomy.

BACKGROUND: Outcome reporting in oncologic surgery has suffered from the lack of a standardized system for reporting operative results particularly complications. This is particularly the case for esophagectomy affecting the accuracy and relevance of international outcome assessments, clinical trial results and quality improvement projects.

METHODS: The Esophageal Complications Consensus Group (ECCG) involving 24 high volume esophageal surgical centers in 14 countries developed a standardized platform for recording complications and quality measures associated with esophagectomy. Using a secure online database (ESODATA.org), ECCG centers prospectively recorded data on all resections according to the ECCG platform from these centers over a two-year period.

RESULTS: Between January 2015 and December 2016, 2704 resections were entered into the database. All demographic and follow-up data fields were $100 \%$ complete. The majority of operations were for cancer (95.6\%) and typically located in the distal esophagus (56.2\%). Some, 1192 patients received neoadjuvant chemoradiation (46.1\%) and 763 neoadjuvant chemotherapy (29.5\%). Surgical approach involved open procedures in $52.1 \%$ and minimally invasive operations in $47.9 \%$. Chest anastomoses were done most commonly (60.7\%) and R0 resections were accomplished in $93.4 \%$ of patients. The overall incidence of complications was $59 \%$ with the most common individual complications being pneumonia (14.6\%) and atrial dysrhythmia (14.5\%). Anastomotic leak, conduit necrosis, chyle leaks, recurrent nerve injury occurred in $11.4 \%, 1.3 \%, 4.7 \%$ and $4.2 \%$ of cases, respectively. Clavien-Dindo complications $\geq$ IIIb 
occurred in $17.2 \%$ of patients. Readmissions occurred in $11.2 \%$ of cases and 30- and 90-day mortality was $2.4 \%$ and $4.5 \%$, respectively. CONCLUSIONS: Standardized methods provide contemporary international benchmarks for reporting outcomes after esophagectomy. 


\section{INTRODUCTION}

Esophagectomy retains an important role in the management of many patients with locally advanced esophageal cancer, often in conjunction with neoadjuvant therapy.

Reviews of national datasets from North America confirm that esophagectomy 30-day mortality remains above 5\%. ${ }^{1}$ National audits and meta-analyses have demonstrated that in-hospital and 90-day mortality, more accurately reflect actual mortality associated with esophagectomy with in-hospital mortality being approximately $7-8 \%$ and 90 -day mortality as high as $13 \%$ when assessed from all centers performing any annual volume of esophageal resections ${ }^{2-4}$. The incidence of complications associated with esophagectomy has been previously reported between $17 \%$ and $74 \%$ 5,6. Irrespective of whether these outcomes originate from national audits or databases from single centers, all of these results have suffered from the absence of a standardized system for documenting and reporting operative outcomes including complications. Previous meta-analyses have documented considerable heterogeneity in the methodology of defining and reporting esophagectomy complications ${ }^{7}$. The absence of a standardized method of reporting perioperative outcomes means that there is no reliable method to compare reports from different institutions or assess the effect of quality improvement initiatives on mortality and perioperative complications. It has also resulted in the failure of the surgical community to generate a truly representative reflection of contemporary short-term outcomes associated with esophagectomy. 
The Esophageal Complications Consensus Group (ECCG) was formed in 2011 and included 21 esophageal surgeons from high volume centers representing 14 countries. Through a series of Delphi surveys and face-to-face meetings, the ECCG developed a standardized platform for reporting mortality, complications and quality measures associated with esophagectomy which was published in $2015^{8}$.

Having produced a system for reporting outcomes associated with esophagectomy, the ECCG agreed to test the system. The hypothesis was that a web-based dataset could be used to document outcomes according to the ECCG platform in international high-volume esophagectomy centers and that this would disclose less variation in complication rates than previously reported. The inclusion of all esophagectomies done over a two-year period within the ECCG centers should provide a contemporary benchmark of morbidity and mortality associated with esophageal resection.

\section{METHODS}

A web-based dataset incorporating all of the data items and definitions published previously was developed to facilitate contemporary data collection ${ }^{8}$. In March 2015, the ECCG reached a consensus regarding additional demographic, surgical and outcomes data fields that were considered critical to collect in addition to the complications platform, definitions and quality measures. Nineteen original ECCG centers and 5 new high volume esophagectomy units agreed to submit patients. (Figure 1) A study protocol was distributed to the study centers. All centers signed the membership agreement (see Supplement 1) and agreed to fulfill all institutional and 
national ethics and IRB requirements in order to supply anonymized patient information to the database. All participating centers agreed to enroll all esophagectomies at their institutions during the study period.

After arriving at a consensus for determining the data fields, face-to-face ECCG meetings were held to review the specific issues involved in the implementation of a web-based international data collection project. Consensus-based data fields and definitions mandated a consistent and "user-friendly" platform to encourage participation while maintaining data integrity and completeness. To overcome variations in computer systems and capabilities between participating centers, a database was developed with secure access that offered a web browserbased interface using existing computer systems without the requirement for additional local resource utilization or IT support other than internet connection involving both desktop and mobile devices. Validation algorithms were built into the database interface to ensure that only validated data was entered.

The database and the web portal were hosted in a high performance, dedicated private web server and the database interface was accessible only via authenticated and encrypted secure network connections (SSL Client and Server Certificate with Extended Validation-Issued by Symantec Corporation). Open-sourced database server package (Maria DB V10.1.21 by Maria DB FOUNDATION) with appropriate backup system arrangements in combination with Drupal content management software (distributed under the terms of the GNU General Public License) was used. This system provided data portability, analytics, modularity and flexibility in content access management. Participating institutes' data-contributing members were authenticated 
individually by the ECCG to access the database's interface and members-only area of the ESODATA.org web portal. Authenticated contributors had instant access to their own institutional results on the ESODATA website that was available to them whenever they had secure internet web access. Contributors received regular email communications every three to four months updating them on patient accrual and intermediate term results.

It was agreed that the study period should run between January of 2015 and December 2016. Data entry began at the time each institution adopted the ECCG platform within their institutional datasets. It was agreed that the study population should yield at least 1200 resections with the goal being to record complications associated with both benign and malignant resections. No formalized system of audit was available for the study although all centers signed and agreed to adhere to the Members Agreement (see Supplement 1). From September 2016, the International Society for Diseases of the Esophagus (ISDE) Executive acted as an external body to provide oversight of the ESODATA website and database.

\section{STATISTICAL METHODS}

The characteristics of the patient population are reported using frequency and percentage for categorical variables and $95 \%$ confidence limits for non-normally distributed continuous variables. The incidence of complications associated with each patient subgroup were also described using frequency and percentage with $95 \%$ confidence limits. Statistical analyses of the present study were performed using SPSS software (version 23.0; IBM Corp., Armonk, NY, USA). 


\section{RESULTS}

From January 2015 to December 2016, 2704 esophagectomies were enrolled in the ESODATA database website. All esophagectomies done at each institution during the study period from the time of the initiation of the ECCG complications platform were included. Data was $100 \%$ complete in all demographic and outcome data fields. Patient demographics and data regarding surgical technique are shown on Table 1. Over $99 \%$ of esophagectomies were elective and $95.6 \%$ of resections were for malignant disease with the most common tumor location being the distal esophagus $(56.2 \%)$.

Within the study population of 2704, 2585 patients underwent esophagectomy for malignant disease. Among the patients undergoing resection for cancer, 1722 patients presented with cT3 disease (66.6\%) and 1395 patients presented with findings of $\mathrm{cN}+(53.9 \%)$ All data for both clinical and pathologic staging are shown in Supplement 2. Of these 2585 patients undergoing esophageal resections for cancer, 1192 patients $(46.1 \%)$ received neoadjuvant chemoradiotherapy, 763 patients (29.5\%) neoadjuvant chemotherapy and $3.1 \%$ had esophagectomy as a salvage operation after definitive chemotherapy. Of the $3.1 \%$ of patients undergoing a salvage resection, $47.5 \%$ underwent their resection more than 12 months after completing chemoradiotherapy. Some 545 patients $(21.1 \%)$ underwent surgery alone.

Data relating to surgical technique are outlined in Table 1. Open operations were more common $(52.1 \%)$, with transthoracic $(79.9 \%)$ being more frequently utilized than transhiatal operations (20.1\%). Minimally invasive procedures were done in $47.9 \%$ with $48.7 \%$ of those operations 
being done with a totally minimally invasive approach. Of the $51.3 \%$ of hybrid procedures, minimally invasive abdominal operations comprised $40.2 \%$ with minimally invasive thoracic procedures comprising $11.1 \%$.

Chest anastomoses were most commonly utilized (60.7\%) and reconstructions utilizing stomach were done in $94.9 \%$ of cases. Two-field lymphadenectomy was reported in $93 \%$ with three-field procedures occurring in 7\%. An R0 resection margin was achieved in $93.4 \%$ of operations.

The overall incidence of complications was $59.0 \%$. In the 1595 patients who sustained complications, 905 (56.7\%) experienced multiple complications (Table 2). Table 3 demonstrates the incidence of individual complications along with the variation (95\% confidence limit) of the incidences of complication within the data contributing ECCG centers. The most common complications were pneumonia (14.6\%) and atrial dysrhythmias (14.5\%). The actual number of complications in each complication groups and variations in individual complication rates among the data contributing ECCG centers is shown in Table 3. Overall, the incidence of anastomotic leak was $11.4 \%$, conduit necrosis $1.3 \%$, chyle leak $4.7 \%$ with recurrent nerve injury in $4.2 \%$. Specific outcomes according to ECCG definitions ${ }^{8}$ are shown in Table 4. Complications graded by the Clavien-Dindo Classification are shown in Table 5 with $17.2 \%$ of patients sustaining complications $\geq$ Clavien-Dindo IIIb.

Mortality was $2.4 \%$ at 30 days and $4.5 \%$ at 90 days (Table 6). Follow-up of 30day mortality and readmissions is $100 \%$ complete. Ninety-day mortality was available in $99.6 \%$ of the study population with eleven out of 2704 patients lost to follow-up between 30 and 90 days of post 
post-op. Readmissions were recorded if they occurred within 30 days of discharge. These occurred for any reason in $11.2 \%$ of patients (Table 6). Of the 275 patients who required readmission related to their esophagectomy, 214 (77.6\%) had experienced post-operative complications. Some 62 (22.4\%) patients required readmission without experiencing inpatient complications. 


\section{DISCUSSION}

Esophagectomy has historically been recognized as one of the most complex major oncologic operations. A meta-analysis of 122 publications including 17 randomized controlled clinical trials and 105 observational studies involving over 57,000 esophagectomies indicated that no complication appeared in all reports and more than $67 \%$ of studies contained no definitions. In addition, 115 reports utilized 10 different methods for reporting mortality ${ }^{7}$. This variability in reporting makes it impossible to make comparisons between national audits or clinical trials or to assess results in response to quality improvement initiatives between institutions.

Accuracy and consistency in reporting complications is critically important. Complications have been directly associated with every other critical outcome parameter associated with the surgical treatment of esophageal cancer. The incidence of complications has been directly linked to operative mortality $^{7,9,10}$, cancer recurrence ${ }^{11,12}$, cancer survival $^{10,13}$, hospital length of stay ${ }^{10,13-15}$, readmissions ${ }^{16-18}$, hospital costs ${ }^{19-21}$, hospital profit margin ${ }^{21}$ as well as health-related quality of $\operatorname{life}^{22-24}$. Generating an accurate reflection of contemporary morbidity and mortality is particularly important as the role of surgery in the treatment of a variety of stages of esophageal malignancy is undergoing continuous assessment.

The ECCG complications platform was not intended to represent every potential problem which may occur following esophagectomy, but developed as a standardized system for reporting the common and relevant aspects of morbidity and mortality associated with esophageal resection. The system utilizes internationally recognized definitions when appropriate, as well as 
definitions previously developed by the ECCG membership notably for anastomotic leak, conduit necrosis, chyle leak and recurrent nerve injury ${ }^{8}$. These specific definitions were considered a critical component as a previous report documented no less than 56 different definitions for anastomotic leak in 97 publications reporting surgical adverse events ${ }^{25}$. The specific definitions enable comprehensive reporting of these important complications reflecting the severity and treatment requirements in all instances, not necessarily represented in either the Accordion ${ }^{26}$ or the Clavien-Dindo ${ }^{27}$ severity stratification systems that report only the most severe complication.

The overall incidence of complications was $59.0 \%$. This incidence of complications is twice that reported in some comprehensive national audits of esophagectomy ${ }^{28}$, and other analyses have demonstrated that complication rates vary enormously between cohorts in different studies ${ }^{5,6}$. When a standardized approach has been applied, as in the present study, this high incidence of complications showed remarkably little variation between the 24 contributing centers (Table 3 ). This suggests that $59 \%$ is more likely to be the true rate of complications after esophagectomy and that previous explanations for variations, reflecting different patient demographics, are no longer tenable.

In some instances, the incidence of individual complications was lower than that seen in previous reports, such as pneumonia with an overall incidence of $14.6 \%$. This may be due to the fact that this report is based on very recent data and modern practice, potentially reflecting the use of standardized clinical pathways, ERAS protocols and a decreased likelihood of failure to rescue $^{29,30}$ in high volume esophagectomy centers. The quality of the contributing centers is 
reflected in a 30-day mortality rate of $2.4 \%, 90$-day mortality of $4.5 \%$ an R0 resection rate of $93.4 \%$ and a readmission rate of $11.2 \%$. These results can be compared to reports of national audits but drawing conclusions will be difficult due to the lack of the focused and standardized system applied in the current study. For example the STS database, although a very well established dataset focuses on staging and procedure specific outcome measures, it does not currently contain the granularity necessary for providing a comprehensive report on short term complications.

The use of a secure online database was designed to improve accessibility while standardizing data input and providing instantaneous reporting of individual institutional data that could be assessed anywhere with internet access along with a format for center-specific internal audit. No center reported difficulties with data entry or access to the system during the course of the study. Ease of access and data entry were likely major contributors to data completeness.

The strengths of the present study include the use of a protocol and dataset specifically aimed to facilitate data collection related to patient demographics and complications associated with esophagectomy. The centers were all high volume units with a history of institutional data collection and previous publications of esophagectomy outcomes. In addition, all individuals entering data were registered and authenticated. All demographic, outcome and complications data entry fields were complete. Follow-up outcomes including 30-day mortality and readmissions data complete in $100 \%$ and 90 -day mortality data was complete in $99.6 \%$ of patients. The dataset is large involving over 2700 patients accrued in a short time period and gathered internationally, making outcomes relevant to current practice at a global level. 
Data entry was simplified using dropdown boxes utilizing modern web browser interface and data entry could take place anywhere that had internet access via HTTPS (Hyper Text Transfer Protocol Secure) network communication.

The present study does have limitations. Other than the signed Members Agreement (Supplement 1), there was no method in place for auditing individual institutional data. The study was not designed, and did not include data on patient quality of life or cancer survival.

These outcomes provide a contemporary benchmark for morbidity and mortality associated with esophagectomy. They reflect current international practice and probably represent the most reliable estimates of esophagectomy outcomes presently available. Secure online data collection has been demonstrated to be a very efficient methodology for carrying out this multi-institution international clinical trial. We predict that this methodology will be utilized regularly in national and international datasets moving forward.

The ECCG system, now overseen by the Research and Database Committee of the International Society for Diseases of the Esophagus (ISDE), should be considered for routine international application in audits and clinical trials as a means of standardizing esophagectomy outcomes. Information on the ESODATA dataset is available at the project web portal (https://esodata.org). 


\section{REFERENCES}

1. Finks JF, Osborne NH, Birkmeyer JD. Trends in hospital volume and operative mortality for high-risk surgery. $N$ Engl J Med 2011;364:2128-2137.

2. Markar SR, Karthikesalingam A, Thrumurthy S, et al. Volume-outcome relationship in surgery for esophageal malignancy: systematic review and meta-analysis 2000-2011. $J$ Gastrointest Surg 2012;16:1055-1063.

3. Walters DM, McMurry TL, Isbell JM, et al. Understanding mortality as a quality indicator after esophagectomy. Ann Thorac Surg 2014;98:506-511.

4. Wright CD, Kucharczuk JC, O'Brien SM, et al. Predictors of major morbidity and mortality after esophagectomy for esophageal cancer: a Society of Thoracic Surgeons General Thoracic Surgery Database risk adjustment model. J Thorac Cardiovasc Surg 2009;137:587-595.

5. Dunst CM, Swanstrom LL. Minimally invasive esophagectomy. J Gastrointest Surg 2010;14 Suppl 1:S108-S114.

6. Courrech Staal EF, Aleman BM, Boot H, et al. Systematic review of the benefits and risks of neoadjuvant chemoradiation for oesophageal cancer. Br J Surg 2010;97:1482-1496.

7. Blencowe NS, Strong S, McNair AG, et al. Reporting of short-term clinical outcomes after esophagectomy: a systematic review. Ann Surg 2012;255:658-666.

8. Low DE, Alderson D, Cecconello I, et al. International Consensus on Standardization of Data Collection for Complications Associated With Esophagectomy: Esophagectomy Complications Consensus Group (ECCG). Ann Surg 2015;262:286-294. 
9. Khuri SF, Henderson WG, DePalma RG, et al. Determinants of long-term survival after major surgery and the adverse effect of postoperative complications. Ann Surg $2005 ; 242: 326-341$.

10. Rizk NP, Bach PB, Schrag D, et al. The impact of complications on outcomes after resection for esophageal and gastroesophageal junction carcinoma. J Am Coll Surg 2004;198:42-50.

11. Lagarde SM, de Boer JD, Ten Kate FJ, et al. Postoperative complications after esophagectomy for adenocarcinoma of the esophagus are related to timing of death due to recurrence. Ann Surg 2008;247:71-76.

12. Lerut T, Moons J, Coosemans W, et al. Postoperative complications after transthoracic esophagectomy for cancer of the esophagus and gastroesophageal junction are correlated with early cancer recurrence: role of systematic grading of complications using the modified Clavien classification. Ann Surg 2009;250:798-807.

13. Luc G, Durand M, Chiche L, et al. Major post-operative complications predict long-term survival after esophagectomy in patients with adenocarcinoma of the esophagus. World $J$ Surg 2015;39:216-222.

14. Hii MW, Smithers BM, Gotley DC, et al. Impact of postoperative morbidity on long-term survival after oesophagectomy. Br J Surg 2013;100:95-104.

15. Schmidt HM, El Lakis MA, Markar SR, et al. Accelerated Recovery Within Standardized Recovery Pathways After Esophagectomy: A Prospective Cohort Study Assessing the Effects of Early Discharge on Outcomes, Readmissions, Patient Satisfaction, and Costs. Ann Thorac Surg 2016;102:931-939. 
16. Kassin MT, Owen RM, Perez SD, et al. Risk factors for 30-day hospital readmission among general surgery patients. J Am Coll Surg 2012;215:322-330.

17. Chen SY, Molena D, Stem M, et al. Post-discharge complications after esophagectomy account for high readmission rates. World J Gastroenterol 2016;22:5246-5253.

18. Doorakkers E, Konings P, Mattsson F, et al. Early complications following oesophagectomy for cancer in relation to long-term healthcare utilisation: a prospective population-based cohort study. PLoS One 2015;10:e0121080.

19. Low DE, Kuppusamy M, Hashimoto Y, et al. Comparing complications of esophagectomy and pancreaticoduodenectomy and potential impact on hospital systems utilizing the accordion severity grading system. J Gastrointest Surg 2010;14:1646-1652.

20. Goense L, van Dijk WA, Govaert JA, et al. Hospital costs of complications after esophagectomy for cancer. Eur J Surg Oncol 2017;43:696-702.

21. Healy MA, Mullard AJ, Campbell DA, Jr., et al. Hospital and Payer Costs Associated With Surgical Complications. JAMA Surg 2016;151:823-830.

22. Derogar M, Orsini N, Sadr-Azodi O, et al. Influence of major postoperative complications on health-related quality of life among long-term survivors of esophageal cancer surgery. $J$ Clin Oncol 2012;30:1615-1619.

23. Scarpa M, Saadeh LM, Fasolo A, et al. Health-related quality of life in patients with oesophageal cancer: analysis at different steps of the treatment pathway. J Gastrointest Surg 2013;17:421-433.

24. Viklund P, Lindblad M, Lagergren J. Influence of surgery-related factors on quality of life after esophageal or cardia cancer resection. World J Surg 2005;29:841-848. 
25. Bruce J, Russell EM, Mollison J, et al. The measurement and monitoring of surgical adverse events. Health Technol Assess 2001;5:1-194.

26. Strasberg SM, Linehan DC, Hawkins WG. The accordion severity grading system of surgical complications. Ann Surg 2009;250:177-186.

27. Dindo D, Demartines N, Clavien PA. Classification of surgical complications: a new proposal with evaluation in a cohort of 6336 patients and results of a survey. Ann Surg 2004;240:205-213.

28. Busweiler LA, Wijnhoven BP, van Berge Henegouwen MI, et al. Early outcomes from the Dutch Upper Gastrointestinal Cancer Audit. Br J Surg 2016;103:1855-1863.

29. Arlow RL, Moore DF, Chen C, et al. Outcome-volume relationships and transhiatal esophagectomy: minimizing "failure to rescue". Ann Surg Innov Res 2014;8:9.

30. Johnston MJ, Arora S, King D, et al. A systematic review to identify the factors that affect failure to rescue and escalation of care in surgery. Surgery 2015;157:752-763. 
FIGURE 1.

Esophageal Complications Consensus Group (ECCG) Data Contributing Center 
FIGURE 1

\section{Esophageal Complications Consensus Group (ECCG) Data Contributing Centers}

\begin{tabular}{|c|c|c|c|}
\hline AUSTRALIA & Brisbane & The University of Queensland & $\begin{array}{l}\text { Mark Smithers } \\
\text { lain Thomson }\end{array}$ \\
\hline BELGIUM & Leuven & Katholieke Universiteit Leuven & $\begin{array}{l}\text { Toni Lerut } \\
\text { Philippe Nafteux }\end{array}$ \\
\hline BRAZIL & São Paulo & University of São Paulo & $\begin{array}{l}\text { Ivan Cecconello } \\
\text { Ulysses Ribeiro, Jr. }\end{array}$ \\
\hline CANADA & Toronto & Toronto General Hospital & Gail Darling \\
\hline CHINA & Hong Kong & Queen Mary Hospital & Simon Ying Kit Law \\
\hline \multirow[t]{2}{*}{ FRANCE } & Lille & Centre Hospitalier Régional Universitaire & $\begin{array}{l}\text { Christophe Mariette } \\
\text { Guillaume Piessen }\end{array}$ \\
\hline & Marseille & Hôpital Nord, Aix-Marseille Université & Xavier Benoit D'Journo \\
\hline \multirow[t]{2}{*}{ GERMANY } & Cologne & University of Cologne & $\begin{array}{l}\text { Wolfgang Schroeder } \\
\text { Marc Bludau }\end{array}$ \\
\hline & Frankfurt & Agaplesion Markus Krankenhaus & Arnulf Hoelscher \\
\hline INDIA & Mumbai & Tata Memorial Hospital & C. S. Pramesh \\
\hline IRELAND & Dublin & Trinity College Dublin & John V. Reynolds \\
\hline JAPAN & Tokyo & Keio University & Yuko Kitagawa \\
\hline \multirow[t]{2}{*}{ NETHERLANDS } & Amsterdam & Academic Medical Center & $\begin{array}{l}\text { Suzanne Gibertz } \\
\text { Mark van Berge Henegouwen }\end{array}$ \\
\hline & Rotterdam & Erasmus Medical Center & $\begin{array}{l}\text { Jan van Lanschot } \\
\text { Bas Wijnhoven }\end{array}$ \\
\hline SPAIN & Barcelona & Hospital Universitario del Mar & Manuel Pera \\
\hline \multirow[t]{4}{*}{ UNITED KINGDOM } & Oxford & Oxford OesophaoGastric Centre & Nick Maynard \\
\hline & Birmingham & Queen Elizabeth Hospital & $\begin{array}{l}\text { Derek Alderson } \\
\text { Sonia Puig } \\
\text { John Whiting }\end{array}$ \\
\hline & London & St. Thomas' Hospital & Andrew Davies \\
\hline & Newcastle & University of Newcastle upon Tyne & Michael Griffin \\
\hline \multirow[t]{5}{*}{ UNITED STATES } & Boston & Massachusetts General Hospital & Christopher Morse \\
\hline & Houston & MD Anderson Cancer Center & Wayne Hofstetter \\
\hline & Pittsburgh & Allegheny Health System & Blair Jobe \\
\hline & Ann Arbor & University of Michigan Health System & Andrew C. Chang \\
\hline & Seattle & Virginia Mason Medical Center & $\begin{array}{l}\text { Donald E. Low } \\
\text { MadhanKumar Kuppusamy }\end{array}$ \\
\hline
\end{tabular}




\section{ACKNOWLEDGMENTS}

This work could not have been accomplished without the constant support of the Thomas Hayward Family. The ECCG expresses their thanks to Admiral Thomas Hayward and his two daughters, Cynthia and Colleen. Special thanks and remembrance to Mrs. Peggy Hayward.

\section{SPECIAL THANKS EXTENDED TO:}

Ms. Bonnie Marston for manuscript preparation.

Dr. MadhanKumar Kuppusamy for developing and technically supporting ESODATA.org during the study. Dr. Andrew Barbour, Dr. David Gotley, Dr. Mark van Berge Henegouwen, Prof. Dr. J.J.B. van Lanschot, Prof. Dr. Toni Lerut, Prof. Dr. Ulysses Ribeiro Jr, Dr. Iain Thomson, Dr. Guillaume Piessen, Dr. John Whiting for their invaluable assistance in project planning and data accrual.

\section{RECOGNITION MUST BE GIVEN TO THE DATA MANAGERS AT THE VARIOUS ECCG CENTERS FOR THEIR ADVICE AND PERSONAL CONTRIBUTIONS TO THE ESODATA DATASET}

\begin{tabular}{ll} 
Name & Institution \\
\hline Janine Thomas & The University of Queensland, Brisbane, Australia \\
\hline Johnny Moons & Katholieke Universiteit Leuven, Leuven, Belgium \\
\hline Emma Small & Toronto General Hospital, Toronto, Canada \\
\hline Jeannette Kwok & Queen Mary Hospital, Hong Kong SAR, China \\
\hline Benjamin Babic & Agaplesion Markus Krankenhaus, Frankfurt, Germany \\
\hline Sinéad King & St James Hospital Dublin, Dublin, Ireland \\
\hline Annelijn E. Slaman & Academic Medical Center, Amsterdam, Netherlands \\
\hline Edith Bouwmeester & Erasmus Medical Center, Rotterdam, Netherlands \\
\hline Marta Gimeno & Hospital Universitario del Mar, Barcelona, Spain \\
\hline Janine Zylstra & St. Thomas' Hospital, London, UK \\
\hline Helen Jaretzke & The Newcastle Upon Tyne Hospitals NHS Foundation Trust, Newcastle, UK \\
\hline Julie Garrity & Massachusetts General Hospital, Boston, USA \\
\hline $\begin{array}{l}\text { Judy Miller } \\
\text { Shari Barnett }\end{array}$ & University of Michigan Health System, Ann Arbor, Michigan, USA \\
\hline Ali H. Zaidi & Allegheny General Hospital, Pittsburgh, Pennsylvania, USA \\
\hline Huawei Tang & MD Anderson Cancer Center, Houston, Texas, USA \\
\hline Andrea Wirsching & Virginia Mason Medical Center, Seattle, Washington, USA \\
\hline
\end{tabular}

One of the most important members of the ECCG passed away in July 2017.

Professor Dr. Christophe Mariette, Head of the Department of Digestive and Oncologic Surgery, CHRU de Lille, France, was an internationally recognized surgeon and academic. He was a friend and counsellor throughout the ECCG project. He will be greatly missed and the Members of the ECCG respectfully dedicate this paper to his memory. 


\section{Table 1 - Patient's Demographics \& Surgical data}

Total patients $=2704$

\begin{tabular}{|c|c|c|}
\hline Gender & $\mathbf{N}$ & N \% \\
\hline Female & 607 & $22.4 \%$ \\
\hline Male & 2096 & $77.5 \%$ \\
\hline \multicolumn{3}{|l|}{ Age group } \\
\hline 40 or less & 66 & $2.4 \%$ \\
\hline $41-50$ & 217 & $8.0 \%$ \\
\hline $51-60$ & 721 & $26.7 \%$ \\
\hline $61-70$ & 1100 & $40.7 \%$ \\
\hline $71-80$ & 532 & $19.7 \%$ \\
\hline More than 80 & 67 & $2.5 \%$ \\
\hline \multicolumn{3}{|l|}{ BMI group } \\
\hline$<18.5$ & 184 & $6.8 \%$ \\
\hline $18.5-25$ & 1085 & $40.1 \%$ \\
\hline $25-30$ & 908 & $33.6 \%$ \\
\hline$>30$ & 526 & $19.5 \%$ \\
\hline \multicolumn{3}{|l|}{$\mathrm{ACCl}$ score groups } \\
\hline $0-3$ & 325 & $12.0 \%$ \\
\hline $4-7$ & 2201 & $81.4 \%$ \\
\hline $8-11$ & 165 & $6.1 \%$ \\
\hline 12 and above & 12 & $0.4 \%$ \\
\hline \multicolumn{3}{|l|}{ ASA status score } \\
\hline 1 & 412 & $15.2 \%$ \\
\hline 2 & 1249 & $46.2 \%$ \\
\hline 3 & 992 & $36.7 \%$ \\
\hline 4 & 49 & $1.8 \%$ \\
\hline 5 & 1 & $0.0 \%$ \\
\hline \multicolumn{3}{|l|}{ WHO / ECOG performance } \\
\hline 0 & 1514 & $56.0 \%$ \\
\hline 1 & 996 & $36.8 \%$ \\
\hline 2 & 136 & $5.0 \%$ \\
\hline 3 & 51 & $1.9 \%$ \\
\hline 4 & 6 & $0.2 \%$ \\
\hline \multicolumn{3}{|l|}{ Comorbidities } \\
\hline Myocardial Infarction & 146 & $5.4 \%$ \\
\hline Congestive Heart Failure & 124 & $4.6 \%$ \\
\hline Chronic Pulmonary Disease & 285 & $10.5 \%$ \\
\hline Peripheral Vascular Disease & 185 & $6.8 \%$ \\
\hline Diabetes Mellitus (uncomplicated) & 348 & $12.9 \%$ \\
\hline Diabetes Mellitus (end organ damage) & 16 & $0.6 \%$ \\
\hline Moderate to Severe Renal Disease & 35 & $1.3 \%$ \\
\hline
\end{tabular}

\begin{tabular}{|c|c|c|}
\hline Timing of surgery & $\mathbf{N}$ & $\mathbf{N} \%$ \\
\hline Elective & 2680 & $99.1 \%$ \\
\hline Emergency & 23 & $0.9 \%$ \\
\hline \multicolumn{3}{|c|}{ Pathology (indication for surgery) } \\
\hline Benign & 97 & $3.6 \%$ \\
\hline Malignant & 2585 & $95.6 \%$ \\
\hline Others, including perforations & 21 & $0.8 \%$ \\
\hline \multicolumn{3}{|l|}{ Tumor location } \\
\hline At the GE Junction & 762 & $28.2 \%$ \\
\hline Proximal $1 / 2$ of esophagus & 304 & $11.2 \%$ \\
\hline Distal $1 / 2$ of esophagus & 1519 & $56.2 \%$ \\
\hline \multicolumn{3}{|l|}{ Surgical approach } \\
\hline Minimally Invasive & 1296 & $47.9 \%$ \\
\hline Open & 1407 & $52.1 \%$ \\
\hline \multicolumn{3}{|l|}{ Open esophagectomy } \\
\hline Trans Hiatal & 283 & $20.1 \%$ \\
\hline Trans Thoracic & 1124 & $79.9 \%$ \\
\hline \multicolumn{3}{|c|}{ Minimally invasive esophagectomy } \\
\hline Abdomen only & 521 & $40.2 \%$ \\
\hline Chest only & 144 & $11.1 \%$ \\
\hline Abdomen and chest & 631 & $48.7 \%$ \\
\hline \multicolumn{3}{|l|}{ Site of anastomosis } \\
\hline Chest & 1641 & $60.7 \%$ \\
\hline Neck & 1025 & $37.9 \%$ \\
\hline Others/None & 37 & $1.4 \%$ \\
\hline \multicolumn{3}{|l|}{ Esophageal conduit } \\
\hline Stomach & 2564 & $94.9 \%$ \\
\hline Colon & 34 & $1.3 \%$ \\
\hline Small bowel & 72 & $2.7 \%$ \\
\hline Others/None & 33 & $1.2 \%$ \\
\hline \multicolumn{3}{|l|}{ Lymphadenectomy neck } \\
\hline No & 2403 & $93.0 \%$ \\
\hline Yes & 182 & $7.0 \%$ \\
\hline \multicolumn{3}{|l|}{ Resection margins } \\
\hline RO - Negative & 2414 & $93.4 \%$ \\
\hline R1 - Microscopic positive & 157 & $6.1 \%$ \\
\hline R2 - Macroscopic positive & 14 & $0.5 \%$ \\
\hline
\end{tabular}

ACCI - Age-Related Charlson Comorbidity Index; WHO - World Health Organization; ECOG - Eastern Cooperative Oncology Group; ASA - American Society of Anesthesiology; BMI - Body Mass Index 


\section{Table 2 - Occurrence of ECCG Complications}

Total patients $=2704$

\begin{tabular}{lrrrrr} 
Complications* & $\mathrm{N}$ & $\mathrm{N} \%$ & $\begin{array}{r}95 \% \text { Lower } \\
\mathrm{CL} \text { for N\% }\end{array}$ & $\begin{array}{r}95 \% \text { Upper } \\
\text { CL for N\% }\end{array}$ & $\begin{array}{r}\text { Standard } \\
\text { Error of N\% }\end{array}$ \\
\hline No & 1109 & $41.0 \%$ & $39.2 \%$ & $42.9 \%$ & $0.9 \%$ \\
\hline Yes & 1595 & $59.0 \%$ & $57.1 \%$ & $60.8 \%$ & $0.9 \%$ \\
\hline $\begin{array}{l}\text { Number of Complications } \\
\text { Occurring in Each Patient }\end{array}$ & & & & & \\
\hline 0 & 1109 & $41.0 \%$ & $39.2 \%$ & $42.9 \%$ & $0.9 \%$ \\
\hline 1 & 690 & $25.5 \%$ & $23.9 \%$ & $27.2 \%$ & $0.8 \%$ \\
\hline 2 & 406 & $15.0 \%$ & $13.7 \%$ & $16.4 \%$ & $0.7 \%$ \\
\hline 3 & 238 & $8.8 \%$ & $7.8 \%$ & $9.9 \%$ & $0.5 \%$ \\
\hline 4 or more & 261 & $9.7 \%$ & $8.6 \%$ & $10.8 \%$ & $0.6 \%$ \\
\hline
\end{tabular}

CL-Confidence Limit; ECCG - Esophagectomy Complications Consensus Group

* - Incidence of complication as per ECCG complication platform definitions 


\section{Table 3. Incidence of Complications and Variation between Centers According to the ECCG Definitions}

\begin{tabular}{|c|c|c|c|c|c|c|c|c|c|c|c|}
\hline Complication Groups* & N & $\mathbf{N} \%$ & $\begin{array}{l}\text { 95\% Lower } \\
\text { CL of N \% }\end{array}$ & $\begin{array}{l}\text { 95\% Upper } \\
\text { CL of N \% }\end{array}$ & $\begin{array}{l}\text { Stand Error } \\
\text { of } \mathrm{N} \%\end{array}$ & Complication Groups* & $\mathbf{N}$ & N\% & $\begin{array}{l}\text { 95\% Lower } \\
\text { CL of } N \text { \% }\end{array}$ & $\begin{array}{l}95 \% \text { Upper } \\
\text { CL of N \% }\end{array}$ & $\begin{array}{l}\text { Stand Error } \\
\text { of } N \%\end{array}$ \\
\hline Gastrointestinal & 606 & $22.4 \%$ & $20.9 \%$ & $24.0 \%$ & $0.8 \%$ & Thromboembolic & 141 & $5.1 \%$ & $4.3 \%$ & $5.9 \%$ & $0.4 \%$ \\
\hline \multirow{2}{*}{$\begin{array}{l}\text { Esophagoenteric leak from } \\
\text { anastomosis, staple line, or } \\
\text { localized conduit necrosis }\end{array}$} & \multirow[t]{2}{*}{307} & \multirow[t]{2}{*}{$11.4 \%$} & \multirow[t]{2}{*}{$10.2 \%$} & \multirow[t]{2}{*}{$12.6 \%$} & \multirow[t]{2}{*}{$0.6 \%$} & DVT & 25 & $0.9 \%$ & $0.6 \%$ & $1.3 \%$ & $0.2 \%$ \\
\hline & & & & & & $\mathrm{PE}$ & 33 & $1.2 \%$ & $0.9 \%$ & $1.7 \%$ & $0.2 \%$ \\
\hline \multirow{2}{*}{$\begin{array}{l}\text { Conduit necrosis/failure } \\
\text { requiring surgery }\end{array}$} & \multirow{2}{*}{34} & \multirow{2}{*}{$1.3 \%$} & \multirow{2}{*}{$0.9 \%$} & \multirow{2}{*}{$1.7 \%$} & \multirow{2}{*}{$0.2 \%$} & Stroke & 4 & $0.1 \%$ & $0.0 \%$ & $0.4 \%$ & $0.1 \%$ \\
\hline & & & & & & Peripheral thrombophlebitis & 79 & $2.9 \%$ & $2.3 \%$ & $3.6 \%$ & $0.3 \%$ \\
\hline \multirow{2}{*}{$\begin{array}{l}\text { Ileus defined as small bowel } \\
\text { dysfunction preventing or } \\
\text { delaying enteral feeding }\end{array}$} & \multirow[t]{2}{*}{46} & \multirow[t]{2}{*}{$1.7 \%$} & \multirow[t]{2}{*}{$1.3 \%$} & \multirow[t]{2}{*}{$2.2 \%$} & \multirow[t]{2}{*}{$0.2 \%$} & Urologic & 224 & $8.3 \%$ & $7.3 \%$ & $9.4 \%$ & $0.5 \%$ \\
\hline & & & & & & \multirow{2}{*}{$\begin{array}{l}\text { Acute renal insufficiency } \\
\text { (defined as: doubling of } \\
\text { baseline creatinine) }\end{array}$} & \multirow[t]{2}{*}{39} & \multirow[t]{2}{*}{$1.4 \%$} & \multirow[t]{2}{*}{$1.0 \%$} & \multirow[t]{2}{*}{$1.9 \%$} & $0.2 \%$ \\
\hline Small bowel obstruction & 12 & $0.4 \%$ & $0.2 \%$ & $0.8 \%$ & $0.1 \%$ & & & & & & \\
\hline Feeding J-tube complication & 27 & $1.0 \%$ & $0.7 \%$ & $1.4 \%$ & $0.2 \%$ & Acute renal failure requiring & 24 & $0.9 \%$ & $0.6 \%$ & $1.3 \%$ & $0.2 \%$ \\
\hline Pyloromyotomy/Pyloroplasty & 5 & $0.2 \%$ & $0.1 \%$ & $0.4 \%$ & $0.1 \%$ & dialysis & & & & & \\
\hline complication & & & & & & Urinary tract infection & 68 & $2.5 \%$ & $2.0 \%$ & $3.2 \%$ & $0.3 \%$ \\
\hline Clostridium Difficile infection & 23 & $0.9 \%$ & $0.6 \%$ & $1.3 \%$ & $0.2 \%$ & Urinary retention requiring & 104 & $3.8 \%$ & $3.2 \%$ & $4.6 \%$ & $0.4 \%$ \\
\hline Pancreatitis & 8 & $0.3 \%$ & $0.1 \%$ & $0.6 \%$ & $0.1 \%$ & $\begin{array}{l}\text { reinsertion of urinary } \\
\text { catheter, delaying discharge, }\end{array}$ & & & & & \\
\hline $\begin{array}{l}\text { GI bleeding requiring } \\
\text { intervention or transfusion }\end{array}$ & 21 & $0.8 \%$ & $0.5 \%$ & $1.2 \%$ & $0.2 \%$ & $\begin{array}{l}\text { or discharge with urinary } \\
\text { catheter }\end{array}$ & & & & & \\
\hline Liver dysfunction & 6 & $0.2 \%$ & $0.1 \%$ & $0.5 \%$ & $0.1 \%$ & Infection & 383 & $14.2 \%$ & $12.9 \%$ & $15.5 \%$ & $0.7 \%$ \\
\hline $\begin{array}{l}\text { Delayed conduit emptying } \\
\text { requiring intervention or }\end{array}$ & 180 & $6.7 \%$ & $5.8 \%$ & $7.6 \%$ & $0.5 \%$ & $\begin{array}{l}\text { Wound infection requiring } \\
\text { opening wound or antibiotics }\end{array}$ & 20 & $0.7 \%$ & $0.5 \%$ & $1.1 \%$ & $0.2 \%$ \\
\hline $\begin{array}{l}\text { delaying discharge or } \\
\text { requiring maintenance of NG } \\
\text { drainage }>7 \text { days post-op }\end{array}$ & & & & & & $\begin{array}{l}\text { Central IV line infection } \\
\text { requiring removal or } \\
\text { antibiotics }\end{array}$ & 55 & $2.0 \%$ & $1.6 \%$ & $2.6 \%$ & $0.3 \%$ \\
\hline Pulmonary & 752 & $27.8 \%$ & $26.1 \%$ & $29.5 \%$ & $0.9 \%$ & Intrathoracic/Intra-abdominal & 65 & $2.4 \%$ & $1.9 \%$ & $3.0 \%$ & $0.3 \%$ \\
\hline Pneumonia & 396 & $14.6 \%$ & $13.4 \%$ & $16.0 \%$ & $0.7 \%$ & abscess & & & & & \\
\hline Pleural effusion requiring & 267 & $9.9 \%$ & $8.8 \%$ & $11.0 \%$ & $0.6 \%$ & Generalized sepsis & 52 & $1.9 \%$ & $1.5 \%$ & $2.5 \%$ & $0.3 \%$ \\
\hline $\begin{array}{l}\text { additional drainage } \\
\text { procedure }\end{array}$ & & & & & & $\begin{array}{l}\text { Other infections requiring } \\
\text { antibiotics }\end{array}$ & 227 & $8.4 \%$ & $7.4 \%$ & $9.5 \%$ & $0.5 \%$ \\
\hline $\begin{array}{l}\text { Pneumothorax requiring } \\
\text { intervention }\end{array}$ & 91 & $3.4 \%$ & $2.7 \%$ & $4.1 \%$ & $0.3 \%$ & Neurologic / Psychiatric & 254 & $9.4 \%$ & $8.3 \%$ & $10.5 \%$ & $0.6 \%$ \\
\hline Atelectasis mucous plugging & 85 & $3.1 \%$ & $2.5 \%$ & $3.9 \%$ & $0.3 \%$ & Recurrent nerve injury & 114 & $4.2 \%$ & $3.5 \%$ & $5.0 \%$ & $0.4 \%$ \\
\hline requiring bronchoscopy & & & & & & Other neurologic injury & 33 & $1.2 \%$ & $0.9 \%$ & $1.7 \%$ & $0.2 \%$ \\
\hline Respiratory failure requiring & 189 & $7.0 \%$ & $6.1 \%$ & $8.0 \%$ & $0.5 \%$ & Acute delirium & 105 & $3.9 \%$ & $3.2 \%$ & $4.7 \%$ & $0.4 \%$ \\
\hline reintubation & & & & & & Delirium tremens & 16 & $0.6 \%$ & $0.4 \%$ & $0.9 \%$ & $0.1 \%$ \\
\hline Acute respiratory distress & 50 & $1.8 \%$ & $1.4 \%$ & $2.4 \%$ & $0.3 \%$ & Wound/Diaphragm & 78 & $2.9 \%$ & $2.3 \%$ & $3.6 \%$ & $0.3 \%$ \\
\hline Acute aspiration & & & & & & Thoracic wound dehiscence & 40 & $1.5 \%$ & $1.1 \%$ & $2.0 \%$ & $0.2 \%$ \\
\hline Acute aspiration & 27 & $1.0 \%$ & $0.7 \%$ & $1.4 \%$ & $0.2 \%$ & Acute abdominal wall & 33 & $1.2 \%$ & $0.9 \%$ & $1.7 \%$ & $0.2 \%$ \\
\hline Tracheobronchial injury & 11 & $0.4 \%$ & $0.2 \%$ & $0.7 \%$ & $0.1 \%$ & dehiscence/hernia & & & & & \\
\hline Chest drain requirement for & 13 & $0.5 \%$ & $0.3 \%$ & $0.8 \%$ & $0.1 \%$ & Acute diaphragmatic hernia & 8 & $0.3 \%$ & $0.1 \%$ & $0.6 \%$ & $0.1 \%$ \\
\hline $\begin{array}{l}\text { air leak for > } 10 \text { days post-op } \\
\text { Cardiac }\end{array}$ & 455 & $16.8 \%$ & $15.5 \%$ & $18.3 \%$ & $0.7 \%$ & Other complications & 185 & $6.8 \%$ & $5.9 \%$ & $7.8 \%$ & $0.5 \%$ \\
\hline Cardiac arrest reguiring $\mathrm{CP}$ & 28 & $1.0 \%$ & $0.7 \%$ & $10.3 \%$ & $0.2 \%$ & Chyle leak & 128 & $4.7 \%$ & $4.0 \%$ & $5.6 \%$ & $0.4 \%$ \\
\hline Myocardial infarction & $\begin{array}{l}20 \\
15\end{array}$ & $\begin{array}{l}1.0 \% \\
0.6 \%\end{array}$ & $0.3 \%$ & $\begin{array}{l}1.5 \% \\
0.9 \%\end{array}$ & $0.1 \%$ & Reoperation for reasons & 39 & $1.4 \%$ & $1.0 \%$ & $2.3 \%$ & $0.2 \%$ \\
\hline Atrial dysrhythmia requiring & 393 & $14.5 \%$ & $13.2 \%$ & $15.9 \%$ & $0.7 \%$ & or conduit necrosis & & & & & \\
\hline intervention & & & & & & Multiple organ dysfunction & 27 & $1.0 \%$ & $0.7 \%$ & $1.4 \%$ & $0.2 \%$ \\
\hline $\begin{array}{l}\text { Ventricular dysrhythmia } \\
\text { requiring intervention }\end{array}$ & 25 & $0.9 \%$ & $0.6 \%$ & $1.3 \%$ & $0.2 \%$ & syndrome & & & & & \\
\hline $\begin{array}{l}\text { Congestive heart failure } \\
\text { requiring intervention }\end{array}$ & 12 & $0.4 \%$ & $0.2 \%$ & $0.8 \%$ & $0.1 \%$ & & & & & & \\
\hline $\begin{array}{l}\text { Pericarditis requiring } \\
\text { intervention }\end{array}$ & 2 & $0.1 \%$ & $0.0 \%$ & $0.2 \%$ & $0.1 \%$ & & & & & & \\
\hline
\end{tabular}

CL-Confidence Limit; ECCG - Esophagectomy Complications Consensus Group; DVT-Deep Venous Thrombosis; PE - Pulmonary Embolus;

CVA - Cerebrovascular Accident; CPR-Cardiopulmonary Resuscitation. * Complication group items include patients with more than one complications. 


\title{
Table 4. Complications Definitions Summary
}

\author{
Total patients $=2704$
}

Anastomotic leak
DEFINITION:
Full thickness GI defect
involving esophagus,
anastomosis, staple line, or
conduit irrespective of
presentation or method of
identification

Conduit necrosis / failure

\section{DEFINITION:}

Postoperative identification of conduit necrosis.
No Leak

Type I: Local defect requiring no change in therapy or treated medically or with dietary modification

Type II: Localized defect requiring interventional but not surgical therapy, for example, interventional radiology drain, stent or bedside opening, and packing of incision

Type III: Localized defect requiring surgical therapy

\section{N $\quad \mathbf{N} \%$}

$240388.9 \%$

$90 \quad 3.3 \%$

$131 \quad 4.8 \%$

$80 \quad 3.0 \%$

No Conduit necrosis

$267298.8 \%$

Type I: Conduit necrosis focal Identified endoscopically

$20.1 \%$

(Treatment-Additional monitoring or non-surgical therapy)

Type II: Conduit necrosis focal Identified endoscopically and not associated

$7 \quad 0.3 \%$ with free anastomotic or conduit leak (Treatment-Surgical therapy not involving esophageal diversion)

Type III: Conduit necrosis extensive (Treatment-Treated with conduit resection with diversion)

\section{Recurrent laryngeal nerve injury involvement}

No Recurrent laryngeal nerve injury

$259596.0 \%$

Type la: Unilateral transient injury requiring no therapy (Dietary modification allowed)

Type Ib: Bilateral transient injury requiring no therapy (Dietary modification allowed)

DEFINITION:

Vocal cord dysfunction postresection. Confirmation and assessment should be by direct examination.

\section{Chyle leak severity}

\section{DEFINITION:}

Milky discharge upon initiation of enteric feeds and/or pleural fluid analysis demonstrating triglyceride level $>100 \mathrm{mg} / \mathrm{dl}$ and/or chylomicrons in pleural fluid
Type Ila: Unilateral Injury requiring elective surgical procedure, for example, thyroplasty or medialization procedure

Type Ilb: Bilateral Injury requiring elective surgical procedure, for example, thyroplasty or medialization procedure

Type IIla: Unilateral Injury requiring acute surgical intervention (due to aspiration or respiratory issues), for example, thyroplasty or medialization procedure

Type IIIb: Bilateral Injury requiring acute surgical intervention (due to aspiration or respiratory issues), for example, thyroplasty or medialization procedure
$12 \quad 0.4 \%$

$4 \quad 0.1 \%$

$20.1 \%$

$4 \quad 0.1 \%$ 


\section{Table 5 - Clavien-Dindo Classification of Surgical Complications}

Total patients $=2704$

\begin{tabular}{lccccc} 
Complication severity & $\mathbf{N}$ & $\mathbf{N} \%$ & $\begin{array}{c}\mathbf{9 5 \%} \text { Lower } \\
\mathbf{C L} \text { for } \mathbf{N} \%\end{array}$ & $\begin{array}{c}\mathbf{9 5 \%} \text { Lower } \\
\mathbf{C L} \text { for } \mathbf{N} \%\end{array}$ & $\begin{array}{c}\text { Standard } \\
\text { Error of N\% }\end{array}$ \\
\hline No Complications* & 1109 & $41.0 \%$ & $39.2 \%$ & $42.9 \%$ & $0.9 \%$ \\
\hline Grade I & 204 & $7.5 \%$ & $6.6 \%$ & $8.6 \%$ & $0.5 \%$ \\
\hline Grade II & 551 & $20.4 \%$ & $18.9 \%$ & $21.9 \%$ & $0.8 \%$ \\
\hline Grade IIIa & 385 & $14.2 \%$ & $13.0 \%$ & $15.6 \%$ & $0.7 \%$ \\
\hline Grade IIIb & 178 & $6.6 \%$ & $5.7 \%$ & $7.6 \%$ & $0.5 \%$ \\
\hline Grade IVa & 173 & $6.4 \%$ & $5.5 \%$ & $7.4 \%$ & $0.5 \%$ \\
\hline Grade IVb & 35 & $1.3 \%$ & $0.9 \%$ & $1.8 \%$ & $0.2 \%$ \\
\hline Grade V & 69 & $2.6 \%$ & $2.0 \%$ & $3.2 \%$ & $0.3 \%$ \\
\hline * No complications as per Esophageal Complication Consensus Group definitions, CL-Confidence Limit
\end{tabular}

Grades Clavien-Dindo Complication severity definitions

Grade I: Any deviation from the normal postoperative course without the need for pharmacological treatment or surgical, endoscopic and radiological interventions

(Allowed therapeutic regimens are: drugs as antiemetics, antipyretics, analgesics, diuretics and electrolytes and physiotherapy. This grade also includes wound infections opened at the bedside)

Grade II: Requiring pharmacological treatment with drugs other than such allowed for grade I complications. Blood transfusions and total parenteral nutrition are also included

Grade IIla: Requiring surgical, endoscopic or radiological intervention - Not under general anesthesia

Grade IIlb: Requiring surgical, endoscopic or radiological intervention - Under general anesthesia

Grade IVa: $\quad$ Single organ dysfunction (including dialysis)

Grade IVb: Multi-organ dysfunction

Grade V: Death of a patient 


\section{Table 6. Readmissions and Mortality status outcomes}

Total patients $=2704$

\begin{tabular}{lrr} 
Readmission within 30 days of discharge & N & N\% \\
\hline No readmission & 2280 & $84.3 \%$ \\
Readmission related to esophagectomy & 275 & $10.2 \%$ \\
Unrelated readmission & 28 & $1.0 \%$ \\
Readmissions status not known & 47 & $1.8 \%$ \\
Not discharged at 30 days or died inpatient & 74 & $2.7 \%$ \\
Perioperative mortality & 56 & $2.1 \%$ \\
\hline Alive after 30 days post-op but died before 90 days & 2572 & $95.1 \%$ \\
Alive after 90 days post-op & 65 & $2.4 \%$ \\
Died within 30 days post-op & 11 & $0.4 \%$ \\
\hline Status not known / lost to follow-up after 30days post discharge & & \\
\hline
\end{tabular}




\section{SUPPLEMENT 1}

\section{Membership Agreement Signed at the Time of Registration on the ESODATA Website Documenting the Responsibility of Contributing Institutions}

\section{ESODATA.org Membership Agreement}

I WILL take part in the analysis and production of manuscripts based on the results of the ESODATA.org data collection.

I WILL NOT share the results of the interim reports sent from esodata.org until formally reviewed for publication by the ISDE-appointed Research and Database Committee.

I WILL comply and fulfill all institutional and national criteria for participation in this study.

I WILL record all patients undergoing esophageal resection at my institution that fulfill the criteria for inclusion during the study period.

I WILL record information accurately, completely and in a timely fashion on the www.esodata.org data collection I will promptly respond to email/correspondence requests for information, data update or opinion to maintain consensus during the study period.

I WILL ensure that data entered is fully anonymized and no identifiable patient information is entered in esodata.org database.

BY SIGNING THIS DOCUMENT, I accept ESODATA.org membership and agree to adhere to all the responsibilities of the Membership Agreement. 


\section{Supplement 2 - Clinical \& Pathological staging data}

Total patients with malignant pathology $=2585$

\begin{tabular}{|c|c|c|c|c|c|c|c|}
\hline \multicolumn{2}{|l|}{ Clinical Stage } & \multirow{2}{*}{$\frac{N}{4}$} & \multirow{2}{*}{$\begin{array}{r}\mathrm{N} \% \\
0.2 \%\end{array}$} & \multicolumn{2}{|c|}{ Pathologic Stage } & \multirow{2}{*}{$\frac{N}{429}$} & \multirow{2}{*}{$\frac{\mathbf{N} \%}{16.6 \%}$} \\
\hline \multirow{7}{*}{ cT stage } & T0 & & & \multirow{7}{*}{ pT stage } & pT0 & & \\
\hline & Tx & 83 & $3.2 \%$ & & pTx & 24 & $0.9 \%$ \\
\hline & Tis & 21 & $0.8 \%$ & & pTis & 30 & $1.2 \%$ \\
\hline & $\mathrm{T} 1$ & 263 & $10.2 \%$ & & pT1 & 584 & $22.6 \%$ \\
\hline & $\mathrm{T} 2$ & 411 & $15.9 \%$ & & $\mathrm{pT} 2$ & 365 & $14.1 \%$ \\
\hline & T3 & 1722 & $66.6 \%$ & & pT3 & 1075 & $41.6 \%$ \\
\hline & T4 & 81 & $3.1 \%$ & & pT4 & 78 & $3.0 \%$ \\
\hline \multirow{5}{*}{ cN stage } & $\mathrm{Nx}$ & 297 & $11.5 \%$ & \multirow{5}{*}{ pN stage } & $\mathrm{pNx}$ & 7 & $0.3 \%$ \\
\hline & NO & 893 & $34.5 \%$ & & pNO & 1477 & $57.1 \%$ \\
\hline & N1 & 1030 & $39.8 \%$ & & $\mathrm{pN} 1$ & 550 & $21.3 \%$ \\
\hline & $\mathrm{N} 2$ & 314 & $12.1 \%$ & & $\mathrm{pN} 2$ & 359 & $13.9 \%$ \\
\hline & N3 & 51 & $2.0 \%$ & & pN3 & 192 & $7.4 \%$ \\
\hline \multirow{3}{*}{ cM stage } & $\mathrm{Mx}$ & 200 & $7.7 \%$ & \multirow{3}{*}{ pM stage } & $\mathrm{pMx}$ & 369 & $14.3 \%$ \\
\hline & MO & 2349 & $90.9 \%$ & & $\mathrm{pMO}$ & 2170 & $83.9 \%$ \\
\hline & M1 & 36 & $1.4 \%$ & & pM1 & 46 & $1.8 \%$ \\
\hline
\end{tabular}

